\title{
Sexually Transmitted Infections and Associated Conditions Among Women Who Have Sex with Women
}

\author{
Devika Singh" and Jeanne M. Marrazzo*
}

Department of Medicine/Division of Allergy and Infectious Diseases, Center for AIDS and STD, Harborview Medical Center/University of Washington, Box 359931, 325 Ninth Avenue, Seattle, WA 98104, USA

\begin{abstract}
Available data support that women who have sex with women (WSW) are at risk for a variety of sexually transmitted infections (STI) and vaginitis. Risk of STI transmission in this group depends on the specific STI under consideration and the sexual practices involved. Data demonstrates that WSW receive less standard gynecologic screening than their heterosexual counterparts. This may be due, in part, to provider and patient assessment of risk. Based on available evidence, there is a need to increase provider education on the sexual health of WSW. Moreover, enhancement of STI screening guidelines that specifically mention WSW, particularly for cervical cancer and infections caused by $C$. trachomatis, are essential.
\end{abstract}

\section{INTRODUCTION}

Despite an increased interest in the field of women's health over the past two decades, relatively few studies have focused on the sexual health of lesbians. The literature, though sparse, does contain important findings in the field of sexually transmitted infections (STI) among women who have sex with women (WSW). Although the body of research on lesbian health is growing, only a limited number of methodologically rigorous, longitudinal studies have explored sexual and reproductive health among WSW. This review highlights sexual health risks and disparities in WSW, a group of women that have been traditionally overlooked in the research arena and often marginalized in society.

Terminology in the field of sexual health can be problematic. The term WSW is often used to describe women who report sex with women. This may, however, capture women currently having sex with women but also those who have a history of recent or remote sex with men. Some may use the term WSEW to describe women who report sex exclusively with women. The term WSMW attempts to captures women who report sex with both men and women. Again, this term is limited in that it may capture some women who are currently having sex with women exclusively but have a very remote history of sex with men. Data gathering tends to be specific, for example, eliciting information from research participants on sex partners within the past 90 days. Other researchers, however, may wish to capture information on sex partners within the past year. Thus, there are no universal definitions for WSW, WSEW and WSMW.

*Address correspondence to these authors at the Department of Medicine/Division of Allergy and Infectious Diseases, Center for AIDS and STD, Harborview Medical Center/University of Washington, Box 359931, 325 Ninth Avenue, Seattle, WA 98104, USA;

Tel: 206-744-8311/3679; Fax: 206-744-3693;

E-mails: dsingh@u.washington.edu,jmm2@u.washington.edu
The word "lesbian" has been used variably, and often carelessly, to convey information about the different axes of sexuality including orientation, identity and behavior [1]. Sexual orientation describes emotional, romantic, or sexual attraction toward others [2]. Sexual identity is a term used to label oneself and may describe a place within a specific community (lesbian, bisexual, or queer, for example). Sexual behavior refers to specific sexual practices with a partner, despite orientation or identity. Researchers often assume that the term "lesbian" communicates relevant information about all three axes. This confusion has been compounded by a relatively widespread assumption that women who selfidentity as lesbian have never had sex with men or are not currently sexually active with men.

Imprecise terminology, assumptions about current and past sexual partnerships, and general ignorance of the complexity of women's sexuality have all contributed to the relative lack of sophisticated, long-term data on the sexual practices and health of a highly diverse group of women.

We recognize the many challenges and limitations in terminology in this field of research. For the purposes of this review, we attempt to use the term WSW to describe data that captures women with primary sexual partnerships with women and the term WSMW to describe data for women that acknowledge sexual partnerships with both men and women.

\section{EPIDEMIOLOGY}

Despite the fact that the social stigma surrounding homosexuality has diminished somewhat over the past few decades, many individuals, fearing community ostracism or employment discrimination, remain reluctant to disclose their sexual behaviors or orientation. The Institute of Medicine, in its 1999 report, Lesbian Health: Current Assessment and Directions for the Future, emphasized that more data is needed on STIs, cervical cancer screening, and risk for cervical cancer in lesbians [3].

WSW have been largely absent from the data collection that drives national disease surveillance and national 
women's health studies, including the Nurse's Health Study and the Women's Health Initiative (WHI). The WHI only began collecting information on same sex behavior or identity in 1998 and the Nurse's Health Study began this in 1995 [4]. According to the 2002 National Survey of Family Growth, which collected reports of sexual behavior using audio computer-assisted self-interviewing (A-CASI), $11 \%$ of women aged 15 to 44 reported same sex behavior in their lifetime (this data was based on a sample of 12,571 men and women) [5]. A-CASI is an important research tool designed to capture information on sensitive topics, such as sexual health and drug use.

The National Survey of Sexual Attitudes and Lifestyles (NATSAL) 2000 study collected information on the sexual behavior of 11,161 residents in Britain aged 16-44 [6,7]. Approximately 1 in 10 women in NATSAL 2000 reported attraction to women with $4.9 \%$ reporting at least one same sex partnership in their lifetime and $2.8 \%$ reporting same sex genital contact in the past five years. In this same study, $98 \%$ of WSW reported a history of sex with men and $85 \%$ reported that they had sex with a man in the past 5 years.

\section{SEXUAL BEHAVIORS}

The majority of WSW (between $80-95 \%$ ) report a sexual history with men, with much of this behavior commencing during adolescence $[8,9]$. Diamant and colleagues surveyed 6,935 self-identified lesbians which they solicited through a survey printed in The Advocate, a U.S.-based national gay and lesbian news magazine. The majority of women in this study $(77.3 \%)$ reported one or more lifetime male sex partners. Of these women, $17.2 \%$ reported having anal intercourse and $5.7 \%$ reported a male sex partner in the past year. According to this study and others, WSW may engage in relatively high risk sexual behaviors including unprotected vaginal and anal sex with homosexual or bisexual men [10].

Consistent with the common report of sexual experience with men, WSW typically report a number of reproductive health outcomes, including pregnancy and induced abortion. Lifetime prevalence of reported pregnancy ranges from $23 \%$ to $35 \%$ among WSW [11, 12]. Among 392 WSW who participated in the Seattle Lesbian Health Study (1998-2001; median age of all subjects, 28 years), $25 \%$ reported a prior pregnancy, over half had used oral contraceptives, and $16 \%$ had had an induced abortion [13].

Other studies have demonstrated high risk behaviors among WSW, including use of injection drugs and crack cocaine, and exchange of sex for drugs or money [14-19]. One relatively large cross-sectional survey across health care sites in the U.S. found that women who identified as lesbians generally reported more male sex partners and specifically higher numbers of homosexual male sex partners in the past year than either heterosexual or bisexual women [20]. This study included 1,304 lesbians, across 33 outpatient primary care sites, who participated in an extensive questionnaire ( 98 items) with a good response rate $(>50 \%)$. Respondents were mostly white, highly educated, and had a relatively high income. Although most women reported being in a stable relationship (71\%), many (23\%) reported substance use while having sex or sex with a homosexual or bisexual man $(6 \%)$ in the past year. Of those women who recently had sex with men ( $\mathrm{N}=600)$, only a little over half reported ever using condoms.

In NATSAL 2000, 70.7\% (95\% CI $61.9-78.5 \%)$ of WSMW as compared with $50.8 \%$ (95\% CI $32-69.3 \%$ ) of WSW reported 1 female partner only in the past 5 years [6]. WSMW, as compared with heterosexual women, reported higher risk sexual encounters including anal sex (ageadjusted odds ratio for WSMW relative to women reporting exclusively heterosexual partners [AOR] 2.41 [95\% CI 1.52$3.81, P<0.05]$ ), most recent partner described as "not regular" (AOR $1.76[95 \%$ CI $1.04-2.97, P<.05$ ), initiating sex less than 24 hours after meeting most recent partner (AOR 2.44 [95\% CI 1.39-4.28, $\mathrm{P}<.05]$ ) and unsafe sex (two or more heterosexual partners in the past 4 weeks with inconsistent condom use; AOR 7.17 [95\% CI 3.25-15.8, $\mathrm{P}<.001]$ ). Moreover, WSW were more likely than heterosexual women to report seeking care at an STD clinic, obtaining an HIV test, being diagnosed with any STI and having had an induced abortion $(\mathrm{P}<0.001$ for each relative to heterosexual respondents).

Differences among WSW and WSMW are noteworthy and warrant separate analyses. In one study of more than 29,000 sexually active female college students, selfidentified bisexual women reported a history of more STIs than either their heterosexual or self-identified lesbian counterparts [21]. In one analysis among WSW, 14-44 years of age, self-reported viral STI rates were significantly higher among self-identified bisexual women $(15.0 \%$ to $17.2 \%)$ than among self-identified lesbians (2.3\% to $6.7 \%)$ [22]. These findings support the need to carefully assess sexual history in terms of prior and current risk behavior for more focused and optimal screening and education.

Table 1 provides an overview of sexual behaviors commonly practiced by WSW. These behaviors (including but not limited to oral sex, receptive vaginal and anal sex with fingers, hands, and shared sex toys) present a plausible means for exchange of infected cervicovaginal secretions and menstrual blood. This possibility is supported by reports of transmission of genital human papillomavirus (HPV), genital herpes, Chlamydia trachomatis, Neisseria gonorrhoeae, syphilis, trichomoniasis and HIV among this group [23-28]. Further discussion on each of these STI and on bacterial vaginosis (BV) follows.

\section{Genital Human Papillomavirus}

Certain strains of HPV cause genital warts, and the majority of cervical and some types of anal cancer. HPV has been detected in WSW including those with no prior history of sex with men. Two Seattle based studies enrolled WSW to assess HPV DNA by PCR-based methods in cervical, vaginal and vulvar samples [25, 27]. Among 150 women in the earlier of these two studies (1995-1997), HPV DNA was present in $30 \%$ of all subjects and in $19 \%$ of those who reported no lifetime history of sex with men. Among all subjects with detectable HPV DNA, 29 (69\%) had unclassified types only, 9 (21\%) had HPV-31/33/35/39, 8 (19\%) had HPV-16, and 1 (2\%) had HPV-6/11. Twentyeight $(62 \%)$ had HPV DNA detected in the specimens from the cervix, $26(58 \%)$ from the vagina, and $32(71 \%)$ from the vulva. Among the 41 woman with HPV DNA who did report 
Table 1. Sexual Practices Among Women who have Sex with Women

\begin{tabular}{|c|c|c|c|}
\hline Practice & Vernacular Name & Estimated Frequency $^{a}$ & Factors Modifying Risk of STD ${ }^{b}$ \\
\hline $\begin{array}{l}\text { Oral- } \\
\text { vulvar/vaginal } \\
\text { contact } \\
\text { (cunnilingus) }\end{array}$ & $\begin{aligned} \text { Going down } & \\
\text { Active } & =\text { Top } \\
\text { Receptive } & =\text { Bottom }\end{aligned}$ & $\begin{array}{l}\text { Very common } \\
\quad(>95 \%)\end{array}$ & $\begin{array}{l}\text { - Presence of oral lesions in active partner (herpes, syphilis, possibly } \\
\text { gonorrhea) }(+) \\
\text { - Use of barriers (plastic wrap, dental dams, condoms) }\end{array}$ \\
\hline $\begin{array}{l}\text { Digital/vaginal- } \\
\text { contact (digital- } \\
\text { anal contact) }\end{array}$ & $\begin{array}{l}\text { Fingering } \\
\text { Fisting } \\
\text { (top or bottom) }\end{array}$ & Very common $(95 \%)$ & $\begin{array}{l}\text { - Sharing of infected cervicovaginal secretions (trichomoniasis, } C \text {. } \\
\text { trachomatis, gonorrhea, HPV, herpes) }(+) \\
\text { - Use of gloves (-) }\end{array}$ \\
\hline Oral/anal contact & Rimming & $\begin{array}{c}\text { Common } \\
(35 \%)\end{array}$ & $\begin{array}{l}\text { - Presence of oral infection in performing partner (syphilis, genital herpes) }(+) \\
\text { - Presence of anorectal infection in receiving partner (hepatitis A, enteric } \\
\text { pathogens) }(+) \\
\text { - Use of barriers }(-)\end{array}$ \\
\hline $\begin{array}{l}\text { Insertive sex toys } \\
\text { (to vagina or anus) }\end{array}$ & Toys, dildos & $\begin{array}{c}\text { Common vaginally } \\
(60 \%) \text { and anally }(25 \%)\end{array}$ & $\begin{array}{l}\text { - Sharing of infected cervicovaginal or anal fluid (trichomoniasis, } C \text {. } \\
\text { trachomatis, gonorrhea, HPV, herpes) }(+) \\
\text { - Use of condoms with sex toys }(-) \\
\text { - Sharing insertive toys without cleansing prior to use }(+)\end{array}$ \\
\hline $\begin{array}{l}\text { Direct genital- } \\
\text { genital contact }\end{array}$ & Tribadism & Very common $(95 \%)$ & $\begin{array}{l}\text { - Direct contact of susceptible skin/mucosa (HPV, herpes, syphilis) }(+) \\
\text { - May involve use of interposed devices, such as vibrators, which can cause } \\
\text { mechanical vulvar irritation }\end{array}$ \\
\hline Sadomasochism & $\mathrm{S} \& \mathrm{M}$, Bondage & Unknown & - Sharing of blood (hepatitis B, C, HIV) (+) \\
\hline
\end{tabular}

prior sex with men, 21 (51\%) had not had sex with a male partner in over a year (range, 1-18 years; median, 2 years). Women with detectable HPV DNA who reported male sex partners were more likely to report a history of receptive oral $\operatorname{sex}(\mathrm{P}=0.05)$.

In the subsequent Seattle Lesbian Health Study (19982001) [27], HPV DNA was measured in 248 women and detected in $31(13 \%)$, including 7 with HPV type 16 and 15 with other oncogenic types. Twelve $(39 \%)$ had nononcogenic types $(6 / 11,40 / 42 / 53 / 54)$. Among the 28 women with HPV DNA who reported prior sex with men, 14 $(50 \%)$ had not had sex with a male partner in over a year (range, 1-11 years; median, 2 years). Importantly, both highand low-grade squamous intraepithelial lesions (SIL) were detected on Papanicolaou (Pap) smear testing in both of these studies, including among women with no history of sex with men. In the first study, 13 (6\% of all subjects) of 150 participants had abnormal Pap smears with 3 of these women reporting no prior sex with men and 3 women reporting female partners with genital warts. Among 248 women enrolled in the second study, 7 of 11 SIL detected occurred in women who reported no prior sex with men or sex with men more than one year previously. Twenty-five women (10\% of all subjects) had abnormal Pap smears. Four women had high-grade and 7 had low-grade SIL with 7 of these lesions occurring in women who reported no history of sex with men or sex with men more than one year prior to testing. HPV DNA was detected in 7 of the 11 women with SIL (HPV-16 in 3 women and other oncogenic types in 4 women). In a large study in an STD clinic in Melbourne, Australia, abnormal Pap smears occurred equally among WSW and heterosexual controls [15].

\section{Genital Herpes}

Genital herpes is classically caused by herpes simplex virus (HSV) type-2 (HSV-2) but can also be secondary to HSV type-1 (HSV-1). Both virus types occur among WSW with some data suggesting that HSV-1 is more prevalent in this population. Western blot assay to detect type-specific antibodies in the sera of 392 women enrolled in the Seattle Lesbian Health Study was completed [26]. Antibodies to HSV-1 were detected in $46 \%$ of samples and antibodies to HSV-2 in $8 \%$. Moreover, HSV-1 seroprevalence increased significantly with increasing numbers of female partners. A sexual history of sex with men was not the only risk factor for HSV seropositivity. Of 78 women who reported no prior sex with men, $3 \%$ were HSV-2 seropositive.

Findings from the Seattle study are slightly disparate from those of the U.S. National Health and Nutrition Examination Survey (NHANES) study that tested sera collected between the years 1999-2004 on a population presumed to be largely heterosexual [29, 30]. The seroprevalence of HSV-2 among women age $20-29$ years old was roughly double (15.6\%) that of the seroprevalance from the Seattle study. This could be explained, in part, by less efficient genital transmission of HSV2 in the absence of penile-vaginal sex. Additionally, the Seattle based study largely comprised white women who reported longterm monogamous partnerships. Predictors of HSV-2 infection in the NHANES study included race, age, lifetime number of sex partners (gender not specified) and marital status. Other predictors included fewer years of formal education, income below the poverty level and history of cocaine use. Of these, increasing age was the only independent predictor for HSV-2 seroprevalence in the Seattle Lesbian Health Study (see Fig. 1). 


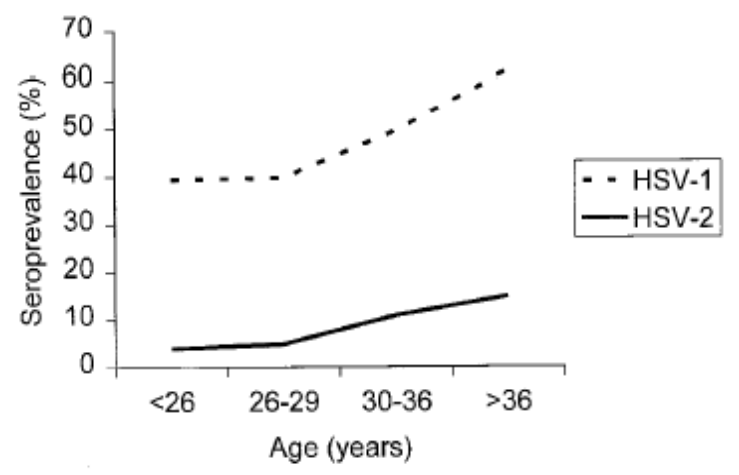

Fig. (1). Seroprevalence of HSV by number of lifetime sex partners (With permission from Marrazzo JM, Stine K, Wald A. Prevalence and risk factors for infection with herpes simplex virus type-1 and 2 among lesbians. Sex Transm Dis 2003; 30: 890-5).

Some studies suggest that the incidence of genital infection with HSV-1 is increasing and that new genital HSV-1 infections are as common as oropharyngeal HSV-1 infections [31-34]. Because genital infection with HSV-1 is most likely acquired during receipt of oral sex, a behavior probably practiced more frequently by WSW than heterosexual women, WSW may be at increased risk. Receptive oral sex in the absence of vaginal intercourse among 1207 heterosexual women prospectively followed in Pittsburgh increased the risk of HSV-1 seroconversion (9.8 vs 1.2 cases per 100 woman-years of follow-up; $P=.04$ ) [33]. Data from the Seattle study supported a stronger association between number of lifetime female sex partners and HSV-1 infection (Fig. 2) than among those who reported male sex partners in the NHANES study [30].

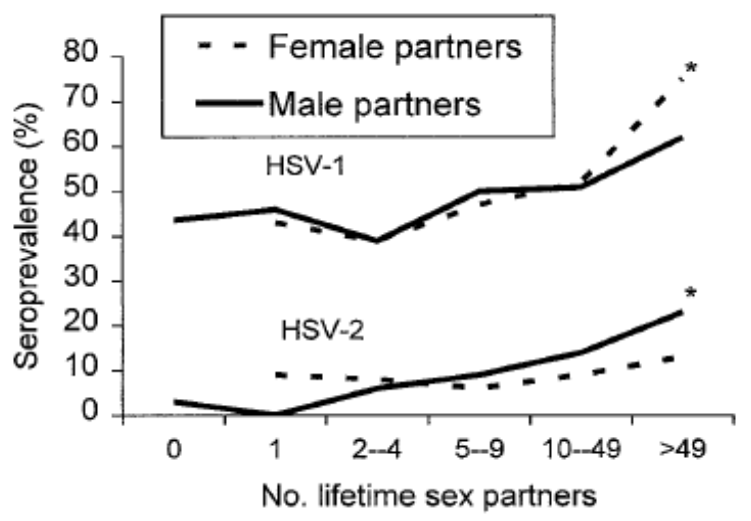

Fig. (2). Sexual behaviors of women who have sex with women (With permission from Marrazzo JM, Stine K, Wald A. Prevalence and risk factors for infection with herpes simplex virus type-1 and 2 among lesbians. Sex Transm Dis 2003; 30: 890-5).

\section{Chlamydia Trachomatis and Neisseria Gonorrhoeae}

Chlamydia trachomatis ( $C$. trachomatis) is the most common bacterial STI in the world, with an estimated 4-5 million cases in the U.S. alone reported annually to the Centers for Disease Control and Prevention (CDC) [35]. C. trachomatis has a major impact on women's sexual and reproductive health. Untreated infections can lead to pelvic inflammatory disease (PID), tubal infertility and chronic pelvic pain. Because the majority of infections in women are asymptomatic and do not cause visible signs of cervicitis, the $\mathrm{CDC}$ and the United States Preventive Services Task Force recommend annual screening for all women aged 24 years and younger [36, 37]. Despite the widespread prevalence of C. trachomatis, little data at the clinic, community or population level is available that describe its prevalence among WSW.

Reliable reports of documented transmission of either $C$. trachomatis or $N$. gonorrhoeae among WSW are rare. For example, among 709 new patients attending a clinic for lesbians in London, prevalence of C. trachomatis was $0.6 \%$ and gonorrhea was $0.3 \%$ [38]. Another study based in an STD clinic in Seattle, Washington, revealed C. trachomatis among only $2(1.1 \%)$ of 187 women reporting sex only with women in the past 2 months and in $12(1.9 \%)$ of 841 women reporting sex with both men and women during that time frame. Gonorrhea was detected in 0 of 192 women and 14 $(2.1 \%)$ of 661 , respectively [18].

A larger study analyzed data from 9358 visits with tests for $C$. trachomatis among WSW and WSMW compared to heterosexual women attending family planning in the U.S. Pacific Northwest from 1997 to 2005. C. trachomatis positivity, a proxy for clinic based prevalence, was $7.1 \%$ among both WSW and WSMW compared with 5.3\% among heterosexual women. Behavioral risks were more commonly reported by women reporting same sex behavior compared to heterosexual women. WSW were more likely to have clinical findings (including cervical ectopy, friable cervix, PID or cervicitis) (OR 3.5 [95\% CI 2.3-5.3], $P<0.05$ ) compared to WSM (OR 3.1 [95\% CI 3.0-3.3], $P<0.05$ ) and WSMW (OR 2.5 [95\% CI 1.7-3.8], $P<0.05)$. Risks for $C$. trachomatis positivity were comparable across the groups and included younger age, non-white race, behavioral risks, and clinical signs [39]. The authors concluded that until more data are available to clarify the epidemiology of and risks associated with this common infection, WSW should undergo routine age-based screening for $C$. trachomatis as recommended for heterosexual women.

\section{Human Immunodeficiency Virus and Syphilis}

Studies suggest that some WSW engage in higher risk sexual behaviors, including sex with men who have sex with men (MSM), relative to their heterosexual counterparts [14, 17]. As such, some WSW are at risk for a number of STI prevalent in MSM. Risk of HIV transmission varies with sexual behaviors, including exchange of cervicovaginal secretions, or exchange of blood in the setting of vulvar or vaginal abrasions, during menses or as a consequence of sexual activity. While no large scale studies have been conducted on WSW and HIV, there have been case reports of HIV transmission between women, including women who report sex exclusively with women [28, 40-44]. Kwakwa and Ghobrial reported a 20 -year-old woman who had had sex exclusively with a bisexual HIV-infected partner for two years prior to being diagnosed with a genetically identical strain of HIV. Reported sexual contact between these two women included oral sex and sharing of sex toys. The newly HIV-infected woman reported that although she never engaged in sex during menses, bleeding during sex had 
occasionally occurred. The investigators excluded alternative explanations, confirming the patient had never shared toothbrushes or razors with her infected partner, injected drugs, received a blood transfusion nor had sex with men.

Transmission of syphilis requires only skin to skin or mucosal contact which can easily occur in the context of sex between women. In fact, sexual transmission of T. pallidum, the causative agent of syphilis, between female partners has been reported [45]. Among WSW who engage in sex with higher risk male sex partners, there may be a higher than usual risk of syphilis acquisition given the recent rise in early infections over the last several years among men who have sex with men [36].

Certain non-sexual risk behaviors including injection drug use (IDU) may be higher among some WSW. In one study that included U.S. surveillance for reported AIDS cases from 1980-1989, 95\% of the 79 women who reported sex with another woman reported current or past IDU [46]. The HIV Epidemiologic Research Study evaluated the sexual behaviors of women who reported prior IDU, had sex with 5 or more partners in the prior 5 years, had a history of sex with a male sex partner at risk for HIV, or had exchanged sex for drugs or money. In this study, 67 of 871 subjects ( $8 \%$ ) had had sex with a woman during the 3.5 years of the prospective follow-up. Most $(82 \%)$ had a history of IDU. A notable weakness of this study was that information on the HIV status of sex partners was not reported.

\section{Bacterial Vaginosis}

Bacterial vaginosis (BV) is a condition that occurs when the hydrogen peroxide-producing Lactobacillus species that characterizes the normal human vagina are replaced by high quantities of commensal anaerobic bacteria. BV is the most common cause of vaginitis among women of reproductive age, and is associated with pelvic inflammatory disease and pre-term labor. BV, though mostly considered significant among women in the context of pregnancy, also increases the risk of STI, including HIV acquisition [47-50].

For reasons that warrant further analysis, the prevalence of BV among WSW is high and vaginal colonization with hydrogen peroxide-producing lactobacilli is low relative to that of heterosexual women matched for age and sexual risk behaviors [51-55]. BV prevalence among lesbians in these studies has ranged from $24 \%$ to $51 \%$, as compared to $21 \%$ for heterosexual STD clinic patients and $9 \%$ to $14 \%$ for pregnant women. Although BV is not a classic STI in that a specific microbial precipitant has not been identified, Criswell and Gardner successfully transmitted BV from one woman to another by the transfer of vaginal secretions in early studies of "Hemophilus vaginalis vaginitis", a historical term for BV [56]. Moreover, Marrazzo and colleagues, utilizing rep-PCR to characterize vaginal isolates among 30 monogamous (defined within the timeframe of the prior 3 months) female sex partners, revealed that 23 of these couples shared identical strains of Lactobacillus. Finally, other studies have demonstrated that BV is frequently found in both members of monogamous lesbian couples and BV concordance within couples has been associated with specific sexual behaviors, including shared use of vaginally penetrative sex toys $[57,58]$.
The common practice of oral sex among WSW may play a part in the high concordance of BV among both members of monogamous lesbian couples, as certain anaerobic bacteria that may also colonize the oral cavity are newly identified agents associated with this condition [58-60]. However, studies that have carefully analyzed a role for oral sex in BV in this population have not consistently reported a positive association. More research is needed in this area.

\section{Trichomoniasis}

In the context of sex between partners that involves potential exchange of cervicovaginal secretions, vaginal infection with trichomonads should be plausible. Interestingly, only one case report of this among WSW is in the literature. Both women in a partnership were infected with Trichomonas vaginalis that was found to be resistant to metronidazole [24]. Among 708 new patients attending a clinic for lesbians in London, trichomoniasis was detected in $1.3 \%$, including women who reported no prior sex with men [38].

\section{PREVENTIVE HEALTH}

One of the most reliable measures of appropriate provision of preventive health among women is cervical cancer screening. Despite the fact that many WSW accurately perceive themselves to be at risk for cervical cancer, Pap smears are performed less frequently than standard guidelines recommend [61-63]. Several investigators have reported that WSW are less likely to undergo routine Pap smear screening and preventive gynecologic care relative to their exclusively heterosexual counterparts [6, 62]. Moreover, as demonstrated in qualitative and quantitative research [20,67], most women who report same sex behavior do not believe that they are at risk of acquiring STI from their female partners. This may lead to less frequent use of preventive measures (for example, washing sex toys between partners) or infrequent use of barrier methods (including gloves, condoms, dental dams) for STI prevention [65]. Finally, health care providers may neglect to obtain a complete sexual history and thus fail to elicit reports from WSW of higher risk behavior that would prompt STI screening and related prevention counseling [66]. Recent research on college aged women revealed that those women who identified as lesbian were the least likely to have had a routine gynecologic examination (46\%, compared with $64-73 \%$ of women who identified as bisexual or unsure versus heterosexual) [21].

Three studies in the U.S. have reported low rates of Pap smear screening among WSW. In the Seattle Lesbian Health Study, $95 \%$ of the respondents believed they should receive Pap smears annually or every 2 years after a normal smear, but $36 \%$ provided a reason for not having done so [27]. Reasons most commonly cited were lack of insurance, adverse experience at prior Pap smear screening, and a belief they did not need it because they were not sexually active with men that was often enforced by physicians. Despite high levels of education and income, women with no prior sex with men were less likely to have ever received a pelvic examination, received their first Pap smear at an older age, and had less frequent Pap smears relative to women who reported prior sex with men. The Boston Lesbian Health Project used snowball sampling to query a national sample 
of 1633 lesbians [67]. Interestingly, while overall screening rates approximated the general population, $39 \%$ of respondents younger than 20 years and $16 \%$ of those $20-29$ years had never had a Pap smear. A study conducted in New York City that utilized a multilingual population-based survey found that WSW were less likely to have had a Pap test in the past 3 years (66 vs 80\%, P<0.0001) and a mammogram in the past 2 years $(53 \%$ vs $73 \%, P<0.0009)$ than other women. Women whose sexual identity and sexual behavior were concordant were more likely to have engaged in healthcare screening practices including Pap smears. In other words, WSW who identified as lesbian were more likely to have received timely Pap tests (97 vs 48\%, $\mathrm{P}<0.0001)$ than those WSW who identified as heterosexual [68].

Many WSW (53\%-72\%) do not disclose their sexual behavior to physicians when they seek care, and disclosures may elicit negative reactions [69]. In a survey of 1,086 WSW, only $43 \%$ with a clear risk factor for HIV perceived themselves to be at risk [64]. Similar assumptions about HPV acquisition from female partners may place these women at risk for delayed detection of cervical cancer by less frequent or no cervical cancer screening. Finally, WSW who do not also have sex with men may not access venues providing hormonal contraception, thus eliminating another routine opportunity for cervical cancer screening to be sought and/or offered.

\section{CONCLUSIONS}

The expanding field of sexual and reproductive health often overlooks the health risks and needs of WSW. Given that WSW appear to be at risk for a full range of viral and bacterial STI, available data highlights the need for more sound science, public health attention and improved provider and patient education. The sexual behaviors of WSW allow transmission of cervicovaginal secretions and blood-borne pathogens, as supported by reports of several STI among women who reported sex exclusively with women. Further research on behaviors and mechanisms of disease acquisition and transmission among WSW, including exploration of higher risk partnerships and behaviors, is needed. Moreover, the available data strongly support efforts to enhance healthcare providers' skill in sexual risk assessment and promote standard screening guidelines for cervical cancer and chlamydia in sexual minority women.

\section{FINANCIAL DISCLOSURES/POSSIBLE CONFLICTS OF INTEREST}

Devika Singh: no potential conflicts; stipend/salary support by: University of Washington, Center for AIDS and STD; Research Training Grant, T32 AI007140-31

Jeanne M. Marrazzo: consultation for Abbott Laboratories.

\section{REFERENCES}

[1] Laumann O, Gagnon JH, Michael RT, Michael S. The social organization of sexuality: sexual practices in the United States. Chicago: University of Chicago Press 1994.

[2] American Psychological Association. Available from: http://www. apahelpcenter.org/articles/article.php. [Accessed: April 10, 2009].

[3] Institute of Medicine, Lesbian health: current assessment and directions for the future. Washington: The Institute 1999.

[4] Department of Health and Human Services. Scientific Workshop on Lesbian Health 2000: Steps for Implementing the IOM Report..
Washington, DC: Office of Research on Women's Health, Department of Health and Human Services, NIH 2000.

[5] Mosher WD, Chandra A, Jones J. Sexual behavior and selected health measures: men and women 15-44 years of age, United States, 2002. Advance Data from Vital and Health Statistics. Hyattsville, MD: National Center for Health Statistics 2005; Vol. 362.

[6] Mercer CH, Bailey JV, Johnson AM, et al. Women who report having sex with women: British national probability data on prevalence, sexual behaviors, and health outcomes. Am J Public Health 2007; 97: 1126-33.

[7] Johnson Am, Mercer CH, Erens B, et al. Sexual behaviour in Britain: Partnerships, practices, and HIV risk behaviours. Lancet 2001; 358: $1835-42$.

[8] Diamant A, Shuster MA, Mcguigan K, Lever J. Lesbians' sexual history with men. Arch Intern Med 1999; 159: 2730-6.

[9] Smith SD, Dermer SB, Astramovich R1. Working with nonheterosexual youth to understand sexual identity development, at-risk behaviors, and implications for health care professionals. Psychol Rep 2005; 96: 651-4.

[10] Lemp GF, Jones M, Kellogg TA, et al. HIV seroprevalence and risk behaviors among lesbians and bisexual women in San Francisco. Am J Public Health 1995; 85: 1549-52.

[11] Johnson SR, Smith EM, Guenther SM. Comparison of gynecologic health care problems between lesbians and bisexual women: a survey of 2,345 women. J Reprod Med 1987; 32: 805-11.

[12] Valanis BG, Bowen DJ, Bassford T, et al. Sexual orientation and health: comparisons in the women's health initiative sample. Arch Fam Med 2000; 9: 843-53.

[13] Marrazzo JM, Stine K. Reproductive health history of lesbians; implications for primary care. Am J Obstet Gynecol 2004; 190: 1298304.

[14] Friedman S, Neaigus A, Jose B, et al. Sociometric risk networks and risk for HIV infection. Am J Public Health 1997; 87: 1289-96.

[15] Fethers K, Marks C, Mindel A, Estcourt CS. Sexually transmitted infections and risk behaviours in women who have sex with women. Sex Transm Infect 2000; 76: 345-9.

[16] Diamant A, Lever J, Schuster MA. Lesbians' sexual activities and efforts to reduce risks for sexually transmitted diseases. J Gay Lesbian Med Assoc 2000; 4: 41-8.

[17] Saewyc EM, Bearinger LH, Blum RW, Resnick MD. Sexual intercourse, abuse and pregnancy among adolescent women: does sexual orientation make a difference? Fam Plan Perspect 1999; 31: 12731.

[18] Marrazzo JM, Koutsky LA, Handsfield HH. Characteristics of female sexually transmitted disease clinic clients who report same-sex behaviour. Int J STD AIDS 2001; 12: 41-6.

[19] Bevier PJ, Chiasson MA, Heffernan RT, Castro KG. Women at a sexually transmitted disease clinic who reported same-sex contact: their HIV seroprevalence and risk behaviors. Am J Public Health 1995; 85: 1366-71

[20] Koh AS, Gomez CA, Shade S, Rowley E. Sexual risk factors among self-identified lesbians, bisexual women, and heterosexual women accessing primary care settings. Sex Transm Dis 2005; 32: 563-9.

[21] Lindley LL, Barnett CL, Brandt HM, Hardin JW, Burcin M. STDs among sexually active female college students: does sexual orientation make a difference? Perspect Sex Reprod Health 2008; 40: 212-7.

[22] Tao G. Sexual orientation and related viral sexually transmitted disease rates among US women aged 15 to 44 years. Am J Public Health 2008; 98: 1007-9.

[23] O'Hanlan KA, Crum CP. Human papillomavirus-associated cervical intraepithelial neoplasia following exclusive lesbian sex. Obstet Gynecol 1996; 88: 702-3.

[24] Kellock DJ, O'Mahony CP. Sexually acquired metronidazole-resistant trichomoniasis in a lesbian couple. Genitourin Med 1996; 72: 60-1.

[25] Marrazzo JM, Koutsky LA, Stine KL, et al. Genital human papillomavirus infection in women who have sex with women. J Infect Dis 1998; 178: 1604-9.

[26] Marrazzo JM, Stine K, Wald A. Prevalence and risk factors for infection with herpes simplex virus type-1 and -2 among lesbians. Sex Transm Dis 2003; 30: 890-5.

[27] Marrazzo JM, Koutsky LA, Kiviat NB, Kuypers JM, Stine K. Papanicolaou test screening and prevalence of genital human papillomavirus among women who have sex with women. Am J Public Health 2001; 91: 947-52.

[28] Kwakwa HA, Ghobrial MW. Female-to-female transmission of human immunodeficiency virus. Clin Infect Dis 2003; 36: e40-1. 
[29] Fleming DT, McQuillan GM, Johnson RE, et al. Herpes simplex virus type 2 in the United States, 1976 to 1994. N Engl J Med 1997; 337: $1105-11$

[30] Xu F, Sternberg MR, Kottiri BJ, et al. Trends in herpes simplex virus type 1 and type 2 seroprevalence in the United States. JAMA 2006; 296: 964-73.

[31] Langenberg AG, Corey L, Ashley RL, Leong WP, Straus SE. A prospective study of new infections with herpes simplex virus type 1 and type 2. Chiron HSV Vaccine Study Group. N Engl J Med 1999; 341: 1432-8.

[32] Lowhagen GB, Tunback P, Andersson K, Bergstrom T, Johannisson G. First episodes of genital herpes in a Swedish STD population: a study of epidemiology and transmission by the use of herpes simplex virus (HSV) typing and specific serology. Sex Transm Infect 2000; 76: 17912

[33] Lowhagen GB, Tunback P, Bergstrom T. Proportion of herpex simples virus (HSV) type 1 and type 2 among genital and extragenital HSV isolates. Acta Derm Venereol 2002; 82: 118-20.

[34] Cherpes Tl, Meyn LA, Hillier Sl. Cunnilingus and vaginal intercourse are risk factors for herpes simplex virus type 1 acquisition in women. Sex Transm Dis 2005; 32: 84-9.

[35] Centers for Disease Control and Prevention. Sexually Transmitted Disease Surveillance, 2007. Atlanta, GA: U.S. Department of Health and Human Services 2009.

[36] Meyers D, Halvorsen H, Luckhaupt S. Screening for chlamydial infection: an evidence update for the U.S. preventive services task force. Ann Intern Med 2007; 147(2): 135-42.

[37] Centers for Disease Control and Prevention. Sexually transmitted diseases treatment guidelines, 2006. MMWR Morb Mortal Wkly Rep 2006; 55(RR-11): 1-100.

[38] Bailey JV, Farquhar C, Owen C, Mangtani P. Sexaully transmitted infections in women who have sex with women. Sex Transm Infect 2004; 80: 244-6.

[39] Singh D, Fine D, Marrazzo J. Chlamydia trachomatis infection among women reporting same sex behavior screened in family planning clinics in the Pacific Northwest, 1997-2005. Presented at CDC Conference on STD in Chicago, Illinois, USA; March 2008; in review for publication.

[40] Marmor M, Weiss LR, Lyden M, et al. Possible female-to-female transmission of human immunodeficiency virus. Ann Intern Med 1986; 105: 969 .

[41] Rich JD, Buck A, Tuomala RE, Kazanjian PH. Transmission of human immunodeficiency virus infection presumed to have occurred via female homosexual contact. Clin Infect Dis 1993; 17: 1003-5.

[42] Troncoso AR, Romani A, Carranza CM, Macias JR, Masini R. Probable HIV transmission by female homosexual contact. Medicina (B Aires) 1995; 55: 334-6.

[43] Monzon OT, Capellan JM. Female-to-female transmission of HIV. Lancet 1987; 2: 40-1.

[44] Gille-Johnson P, Blaxhult A. A case report. Sexually transmitted HIV between two women. Lakartidningen 1996; 93: 3382.

[45] Campos-Outcald D, Hurwitz S. Female-to-female transmission of syphilis: a case report. Sex Transm Dis 2002; 29: 119-20.

[46] Chu SY, Buehler JW, Fleming PL, Berkelman RL. Epidemiology of reported cases of AIDS in lesbians, United States 1980-89. Am J Public Health 1990; 80: 1380-1.

[47] Ness RB, Kip KE, Soper DE, et al. Bacterial vaginosis (BV) and the risk of incident gonococcal or chlamydial genital infection in a predominantly black population. Sex Transm Dis 2005; 32: 413-7.

[48] Wiesenfeld HC, Hillier SL, Krohn MA, Landers DV, Sweet RL. Bacterial vaginosis is a strong predictor of Neisseria gonorrhoeae and Chlamydia trachomatis infection. Clin Infect Dis 2003; 36: 663-8.
[49] Yoshimura K, Yoshimura M, Kobayashi T, Kubo T, Hachisuga T, Kashimura M. Can bacterial vaginosis help to find sexually transmitted diseases, especially chlamydial cervicitis? Int J STD AIDS 2009; 20 : $108-11$.

[50] Hillier S. Normal genital flora. In: Holmes KK, Sparling PF, Stamm WE, et al., Eds. Sexually transmitted diseases. 4th ed. New York: McGraw-Hill 2008; pp. 289-308.

[51] Edwards ATR. Sexually transmitted diseases in lesbians. Intl J STD AIDS 1990; 1: 178-81.

[52] McCaffrey M, Varney P, Evans B, Taylor-Robinson D. Bacterial vaginosis in lesbians: evidence for lack of sexual transmission. Intl J STD AIDS 1999; 10: 305-308.

[53] Bailey JV, Farqhuar C, Owen C. Bacterial vaginosis in lesbians and bisexual women. Sex Transm Dis 2004; 31: 691-4.

[54] Pinto VM, Tancredi MV, Tancredi NA, Buchalla CM. Sexually transmitted disease/HIV risk behaviour among women who have sex with women. AIDS 2005; 19(Suppl 4): S64-S69.

[55] Marrazzo JM, Antonio M, Hillier Sl. Distribution of genital Lactobacillus strains shared by female sex partners. J Infect Dis 2009; 199: 680-3.

[56] Criswell BS, Charles L, Gardner HL, Dukes CD. Haemophilus vaginalis: vaginitis by inoculation from culture. Obstet Gynecol 1969 33: 195-9.

[57] Berger BJ, Kolton S, Zenilman JM, Cummings MC, Feldman J, McCormack WM. Bacterial vaginosis in lesbians: a sexually transmitted disease. Clin Infect Dis 1995; 21: 1402-5.

[58] Marrazzo JM, Koutsky LA, Eschenbach DA, Agnew K, Stine K, Hillier SL. Characterization of vaginal flora and bacterial vaginosis in women who have sex with women. J Infect Dis 2002; 185: 1307-13.

[59] Schwebke JR, Richey CM, Weiss HL. Correlation of behaviors with microbiological changes in vaginal flora. J Infect Dis 1999; 180: 16326.

[60] Tchamouroff SE, Panja SK. The association between receptive cunnilungus and bacterial vaginosis. Sex Trans Infect 2000; 76: 144-5.

[61] Cochran SD, Mays VM, Bowen D, et al. Cancer-related risk indicators and preventive screening behaviors among lesbians and bisexual women. Am J Public Health 2001; 91: 591-7.

[62] Aaron DJ, Markovic N, Danielson ME, Honnold JA, Janosky JE, Schmidt NJ. Behavioral risk factors for disease and preventive health practices among lesbians. Am J Public Health 2001; 91: 972-5.

[63] Fish J, Anthony D. UK national lesbians and health care survey. Women Health 2005; 41:27-45

[64] Einhorn L, Polgar M. HIV-risk behavior among lesbians and bisexual women. AIDS Educ Prev 1994; 6: 514-23.

[65] Marrazzo JM, Coffey P, Bingham A. Sexual practices, risk perception and knowledge of sexually transmitted disease risk among lesbian and bisexual women. Perspect Sex Reprod Health 2005, 37: 6-12.

[66] Kurth AE, Martin DP, Golden MR, et al. A comparison between audiocomputer-assisted self-interviews and clinician interviews for obtaining the sexual history. Sex Transm Dis 2004; 31: 719-26.

[67] Roberts SJ, Sorensen L. Health related behaviors and cancer screening of lesbians: results from the Boston lesbian health project. Women Health 1999; 28: 1-12.

[68] Kerker BD, Mostashari F, Thorpe L. Health care access and utilization among women who have sex with women: Sexual behavior and identity. J Urban Health 2006; 83: 970-9.

[69] Cochran S, Mays VM. Disclosure of sexual preference to physicians by black lesbian and bisexual women. West J Med 1988; 149: 616-9. 